CHAPTER 36

\title{
LIGHTNESS AND WEIGHT: (RE)READING URBAN POTENTIALITIES THROUGH PHOTOGRAPHS
}

\author{
CIAN O'CALLAGHAN
}

First published in Area (2012), 44(2), 200-207.

Red balloons on the industrial skyline

An entire multiplicity rumbles underneath the sameness of the idea (Deleuze 1994: 344).

Time flows in an extraordinarily complex, unexpected, complicated way... (Serres with Latour 1995:58).

For Serres, the city is an imperfect citation perpetually reproducing and transforming itself. No matter how deep we dig into its historical layers '...another point always interpolates itself iteratively, in front of it. One city demands another city, one history requires another; but we do not really know how time flows' (Serres 1991:39, in Crang and Travlou 2001:174). Time and space, for Serres, are 'pleated' in that other temporalities and spatialities are always suggested in any given moment in any given place. Thus, the city always escapes from the net of totalising narratives that seek to encapsulate it, wriggles free of the 'Gods-eye' view, eludes the orderly vision of what de Certeau (1984) calls the 'concept city'. Cities exist in a state of relational tension between attempts to represent them and their inherent multiplicity. As such, the city is a constantly shifting spasm of relations, writhing in and out of the flows of movement and stasis, which can be apprehended in moments of (perceived) unitary meaning before again dissolving into the ether of urban flux.

The visions seated within these moments of unitary meaning can of course exert considerable weight, framing not only what cities are but forming what they will become. Nowhere is this more apparent than in the powerful vision of post-industrial urbanism seated within particular forms of neoliberal capitalist accumulation. An integral part of how the city has been '...colonized and commodified, bought and sold, created and torn down, used and abused, speculated on and fought over' (Merrifield, 2002:89) in capitalism's quest for perpetual growth is through the articulation of these relationships within urban visions (Lefebvre, 1991). Capitalism has been very successful in colonising cities in material and discursive ways, imbuing urban space with its inherent logic and occluding other visions. These visions exert weight, especially in their ability to retain an illusion of consistency while perpetually mutating. But these visions are also paradoxically light in the sense that they are 
contingent upon the alignment of fragmented discursive and material forces.

As I was preparing my $\mathrm{PhD}$ thesis for submission in the summer of 2008, these contradictions presented themselves to me in urgent and insistent ways. During this period the global credit crunch was underway, and the inklings of the national recession were beginning to be felt in Ireland. The context in which this research project was initiated, however, was quite different. The Celtic Tiger boom, which prevailed between 1993 and 2007, transformed Ireland from a weak, peripheral nation to a hightech economy with a GDP double that of many of its European neighbours (Bartley and Kitchin, 2007). One major component of this boom, particularly in the period after 2002, was the cultivation of an ultimately fatal property bubble, which dramatically altered the Irish urban landscape (Kitchinet al., forthcoming). While major regeneration programmes had been rolled out in Dublin from the late 1980s, similar schemes were not implemented in Cork until a decade later, such that the coming to fruition of a major strategy to redevelop the city's docklands coincided with the collapse of the property market, thus rendering the aspirations of this vision obsolete. My thesis concerned urban regeneration in Cork city between 2000 and 2008, and was particularly interested in the way in which the plans for the docklands and the European Capital of Culture (ECOC) event discursively stimulated new city imaginaries and development objectives. In many ways, these strategies had transformed the city (and particular spaces in it), but at the same time much of this functioned in terms of plans that were yet to be physically implemented. Significantly, the city's industrial waterfront was constructed as a space through which Cork would be 'transformed' into a modern European post-industrial city:

The major opportunity site within the [Cork] city boundary is the Docklands area, which has the capacity for the development of a new modern mixed use district bringing both employment and residents back into the city centre, consolidating Cork as 'a European location for enterprise' (Cork City Council, 2002:8).

Despite the fact that the bulk of these transformations were then only existent as urban plans, the images which circulated through strategy documents, promotional texts and developer's plans had begun to take on qualities in certain ways seemingly more 'real' than the spaces as they currently were. It seemed that this change was inevitable, and we were just waiting for the physical to catch up with our mental image. However, this impending transformation was contingent upon the relationships between a set of conditions, the unity of which was threatened by the impending recession. The set of assumptions upon which my research was built, like the property bubble itself, were fast becoming a flimsy foundation. As I was finishing my thesis, the city stood on the thin and anxious line between movement and stasis. 
During this period I captured a photograph (Plate 1), which for me resonated strongly with the themes of my research, the set of urban relations that this was based on, and the tensions on these relationships that the current moment engendered. The image showed a number of old industrial buildings along the waterfront being suspended from what looked like red balloons, and gave the impression that these structures were levitated by the balloons.

In this article $I$ wish to use this image to illustrate a number of exploratory points. Drawing on recent debates on visual methodologies, I acknowledge that capturing images forms a situated fieldwork practice through which we produce relations. I view images not as neutral representations of an objective material reality but as encoding a series of relationships that are read in fluid ways. I want to use this starting point to think about the value (and our use) of images in urban geographical fieldwork.

Through powerful progress visions the city can become in a sense enslaved by a particular urban narrative. Thus, through the discourses of Celtic Tiger expansion and the more uniform trend towards entrepreneurial urbanism, cities like Cork are bound into an uncritical conception of the city as a space to invest in particular forms of economic, cultural and social functions. This view of what the city 'should be' is normalised through various intersecting discourses to the extent that the rationale underpinning it becomes an invisible assumption beyond the need for explanation. The use of images in urban studies literature is also contingent upon these narratives, and thus always implies a temporal dimension through which these images are read. Therefore, if we revisit and reread these images we can disrupt both the 'general' hegemonic inscription and our own encoding of them.

Reading the photograph through Benjamin's 'imagistic approach' to the city and Serres' theorising of space and time as pleated, the underlying agenda of the article is to find oblique pathways to illuminate alternative versions of the (capitalist) city. In relation to the thrust of this article, but also I think applicably more generally, is the potential of the current crisis to provide a pivot around which we can orchestrate a rereading of the multiple cities inherent in images.

\section{Urban images}

The way in which social researchers understand and mobilise images as part of fieldwork has changed much in recent years (Crang, 2003; Fyfe and Law, 1988; Lorimer, 2003; Rose 2003, 2007). Images are now increasingly viewed as one of the primary means by which we construct our world; not simply artefacts or records but reflections of power relations which themselves have their own agency. This article is cognisant of Rose's (2007) assertion that we need to 'take images seriously' and engages in what she calls 'critical visual methodology'. 
By 'critical' I mean an approach that thinks about the visual in terms of the cultural significance, social practices and power relations in which it is embedded; and that means thinking about the power relations that produce, are articulated through and can be challenged by, ways of seeing and imaging (Rose, 2007:xv).

Figure 1. 'Red balloons' over industrial buildings in Cork docklands. 'Balloon', installation by Sorcha O'Brien and Eli Caamano, commissioned by the National Sculpture Factory, Cork

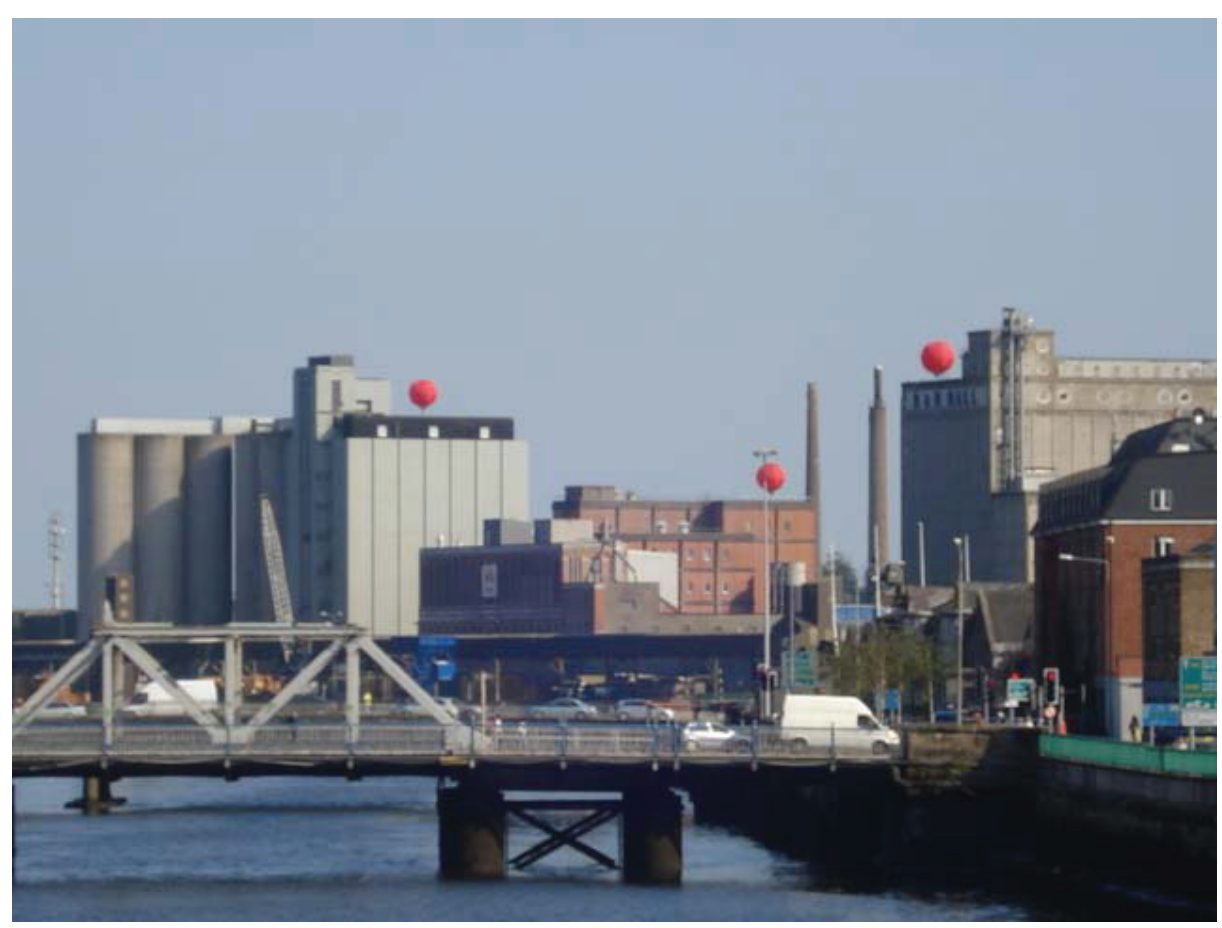

Source: Photo by author

As Rose (2007:2) suggests '. . . images are never transparent windows onto the world. They interpret the world; they display it in very particular ways'. This applies to images that urban geographers collect in the process of fieldwork. While on the surface many such images offer representations of the material world, in reality they are used to demonstrate a range of urban processes, cultural meanings and circuits of capital. These images, therefore, are deeply entwined in a complex web of associations linking the epistemology of research practice with the perceived nature of evolving spatial processes. In this way they are both the embodiment of dominant urban potentialities and our own commentaries and critiques (as researchers) of them. With this in mind it is perhaps useful to revisit and reread our own images in order to understand the ways in which we have constructed meanings through them and how they can begin to form new meanings and associations. 
A sympathetic counterpart to such an agenda can be found in Walter Benjamin's 'imagistic approach' to the city. For Benjamin, photography was a practice that did not simply 'document' the city, but situated the researcher at 'important points in the sphere of imagery' (Gilloch, 1997:18). Benjamin's 'imagistic approach' is not based on images per se but on the ontological implications of seeing explanatory partialities expressed in fragments. He suggests that '...image is dialectics at a standstill. For while the relation of the present to the past is a purely temporal, continuous one, the relation of what-has-been to the now is dialectical: it is not progression but image, suddenly emergent' (Benjamin, 1999:462).

Benjamin's concern with the depiction of the urban is interwoven with a conscious refusal of or resistance to the presentation of an overarching, integrated, coherent view of the city as a whole. The imagistic approach highlights the fleeting, fluid character of the modern metropolitan experience (Gilloch, 1997:18).

While, for Benjamin, the city cannot be apprehended as a whole, it can be (partially but meaningfully) explicated through the broader processes inherent within the moment caught fleetingly and extrapolated creatively by the researcher; 'Indeed to detect the crystal of the total event in the analysis of the small, individual moment' (Benjamin in Gilloch, 1997:112). If we are to view images of the city in the context of Benjamin's imagistic view of cities, then photographs are not representations of static urban relations but points through which we can articulate and rearticulate these relations iteratively.

\section{The fragmented flaneur}

In September 2008 I was, like most doctoral candidates in their final stages of writing up, a hollow shell of my former self. I had spent the previous few months within a narrow time-space geography that mostly involved a circuitous route between a few rooms as I sat writing for most of the day and thinking about writing for the rest. Fragments of sentences rattled around my head as I tried to sleep at night and I rattled around town on some of my few days off, the fragmented flaneur anxiously reading my research on the city. This anxiety familiar to the final stages of a $\mathrm{PhD}$ was not helped by the quickly shifting circumstances of Irish economy and society, which problematised a number of my findings. I began to think that my thesis could quickly move from being a document of contemporary and future urban trends in Cork, to a piece of historical geography illustrating an aborted plan of expansion.

As I took a walk through the city centre one September Saturday shortly before my submission, I was confronted by an uncanny spectacle that encapsulated for me both the understanding I had of urban processes in Cork and my anxieties about my attempts to represent them. I stood on 
St Patrick's bridge looking at the industrial docklands that expanded to the east of the city centre, both an imposing physical presence of concrete and steel and an ever-present weight on my consciousness. A number of the industrial buildings along the south docks floated under red balloons. In a playful exposition obliquely reflecting Kundera's (1984) discourse on lightness and weight, the materiality of these buildings seemed to be lifted through the ethereality of the balloons: heavy industry made feathery by the unbearable lightness of art.

For anyone familiar with the development of urban trends in western cities over the last 30 years, such a connection will resonate. The postindustrial city has been characterised by the co-dependence of capital and culture in the replacement of industrial spaces with those of the knowledge economy, amenity, and art (Chang and Huang, 2005; Gibson and Stevenson, 2004; Gospodini, 2006; Hannigan, 1998; Kong 2000; Miles, 1997; Soja, 2000). The image also resonates with a more localised manifestation of this urban narrative. From the beginning of the previous decade a dual strategy has evolved in Cork that connected the plans to redevelop the waterfront with the re-imagining of the city's image through the ECOC event. Within the discourses of urban planning and development, this strategy enabled new narratives to be formed around notions of Cork as a city experiencing an 'urban renaissance', with new building activity reflecting the emergence of new knowledge and cultural industries (O'Callaghan and Linehan, 2007). Since hosting the 2005 event the City Council and various development interests have sought to draw art into a dialogue with urban transformation, particularly in relation to the space of the docklands. More specifically, these buildings themselves were (at that time) slated for demolition to make way for '...three million sqft of offices and over 1,200 apartments... along with a neighbourhood centre with shops and other facilities...' (Barker, 2008). Thus, the spectacle did not merely relate to an abstract vision of what might happen to this site sometime in the future, but to very immediate material transformations.

These red 'balloons' which caught my attention were in fact attached to the buildings with wire - supported by, rather than supporting these structures - as part of an art installation by Sorcha O'Brien and Eli Caamano, commissioned by the National Sculpture Factory to celebrate Culture Night (an evening of free arts events) in the city. As a public installation it was very effective; working as a clever and visually arresting aesthetic juxtaposition of shape and colour. The hard edges of the angular grey buildings suspended under the contours of the round red balloons. The piece works because of its aesthetic simplicity, perhaps even whimsy. However, and crucially, it suggests relationships that give it depth. 


\section{The moment of the red balloons}

This piece of public art was produced within a certain set of relationships between culture, the city and property development. Reading these relationships within the piece, I composed the shot, framed the landscape in the camera's gaze and captured the image. In this I not only framed visually what was already 'present' but integrated the photograph into a frame of analysis that called various absences to bear upon it. Within the moment of the red balloons I articulated an image that caught/posed the city in a spasm of relations.

The moment of the red balloons formed in Benjamin's terms a 'dialectical image' - 'a moment of interruption and illumination, in which past and present recognise each other across the void which separates them' (Gilloch, 1997: 113) - in relation to my research practice. It provided both a monad (the universal discernible within the particular) that expressed Cork's contemporary urban narrative and a dialectical image that intersected past and present and placed different visions of progress into a relational tension.

Serres suggests that cities do not succeed one another, but rather geography 'presents us with a sowing' (Serres, 1991: 30, cited in Crang and Travlou, 2001: 162), wherein the traces of past cities are pleated in the subsequent cities that emerge. For Serres and Benjamin, modernity and anachronism always coexist. As Serres puts it, '...we are always simultaneously making gestures that are archaic, modern, and futuristic'. Rather than time being linear, it 'percolates' through a turbulent pleating together of these categories.Serres suggests the metaphor of the River Seine to illustrate this point, indicating that while the Seine, like the classical view of time, 'flows' in one direction towards the English Channel 'many little trickles turn back toward Charenton or upstream', thus indicating how the flow of time does not obliterate the past, and is more chaotic than its measurement though universal increments of days, months, and years would imply (Serres with Latour, 1995: 57-62). Events that occurred thousands of years ago can be culturally 'closer' to us than others separated by a much shorter duration because our perception of events is dependent on our folding together different sets of knowledge in ways that are partially 'rational' but also turbulent and affective. Serres (with Latour, 1995: 60) likens this to ironing out and then crumpling up a handkerchief, thus bringing distant points on the flat plane into proximity.

Benjamin's (1999) reading of the city in The Arcades Project is similar. As Buck-Morss (1989) points out, by the time Benjamin chose to study them, the Parisian arcades were already anachronisms. In them, Benjamin witnessed the shimmering array of commodities '[h]ollowed out and barren...revealed as nothing other than a ruin' (Gilloch, 1997: 136). But rather than conceiving of them simply as historical 'artefacts', Benjamin uses the arcades to launch a critique on both the transience of 
commodity forms and the intransigence of capitalist modes of producing the city. As Edensor (2005: 15) suggests, ruins '...gesture towards the present and the future as temporal frames which can be read as both dystopian and utopian, and they help to conjure up critiques of present arrangements and potential futures'. The ruin exposes the myth of eternal progress and, thus, the contradictions of capitalism. In recognising the illuminations of the modern capitalist city in the arcades, Benjamin not only critiques this particular instance of how new spaces are transformed into ruins through creative destruction, but grasps the broader implications of how ruins function as sites shifting between obsolescence and opportunity.

The image under discussion here similarly depicts ruins in complex ways. The industrial buildings on Cork's waterfront are articulated as ruins through the strategy to redevelop the docklands. They are imagined as the artefacts of a dead economic era, which are already consigned to the realm of heritage, their materiality a mere formality. Thus, the docklands strategy produces a ruin space in order to usher in a new phase of capitalist development. When read this way these ruins are utopian, sites of potentiality and opportunity. They stand on the precipice of a becoming commodity - 'The major opportunity site within the city boundary...' (Cork City Council, 2002: 8) - as sites in which the past and the present are projected into an imagined future. However, in recognising this shifting position of the ruin, how it is simultaneously urban blight and opportunity - as we can do through this photograph - we destabilise the legitimacy of the linear view of development. The combination of art and urban development, the industrial with the postindustrial, and its intersection with powerful urban imaginaries concerning accounts of what the city 'has ceased to be' and 'will become' placed the moment of the red balloons at an interface of urban pasts and potential futures. The pleated histories of space comingle in an image that seems to 'move' figuratively to unveil urban complexity. Within this image, visions of the future coalesce and coexist among the ruins of the past, pasts rendered ruin by the pathways of progress mapped out in the strategies of the present day, while the ungainly tension between these trajectories is obliquely animated by the punctuation of the red balloons. Thus, in rendering this irreconcilable juxtaposition of past, present and future visible the red balloons explode the myth of linear progress by calling to attention the space (and the city) as one of mixture and multiplicity. The moment of the red balloons articulates the shifting mingled relationships between the city as commodity, opportunity, and ruin, between past, present and future.

But there is a double-bind here. The subsequent unravelling of the surety of the entrepreneurial vision of the city further dissolves the boundaries between these coordinates. The commodification of the city's future encapsulated in this vision is itself exposed as ruin. The photograph, thus, becomes also a depiction of a ruin of what never was. At the time I 
took this photograph it not only suggested to me the form of urban development practiced in Cork, it also suggested to me the fragility of this system. In doing so, it exposed for me the apparatus of entrepreneurial urbanism - seemingly so entrenched in the urban political economy - as a tenuous alignment of a fragmented set of relations poised to fall apart at any moment. With the country sliding into recession and the world poised on the precipice of financial meltdown, it reflected the city tethering on a thin and anxious line between movement and stasis. Given the then impending demolition of these buildings, the warm red of the balloons seemed to float in an eerie silence over the deserted buildings, highlighting their temporality, but also their physicality. In this way, they seemed to me almost like a question mark. As Cork stood on the cusp of a new phase of development, the balloons looked set to take off, to lift these buildings - relics of an industrial past - and clear the way for change. But, like the city itself, they were still anchored to the ground; tenuously tugging at flight, but with roots deep in the landscape.

If I look upon the photograph now, there is less of a sense of struggle. The extravagant plans for the docklands are gradually vanishing into the fog of recession. In 2009, it was announced that planning permission had been granted for three new bridges that were seen as central infrastructural provisions for the docklands project. However, as this story adorned the front page of the local newspaper, it sat side-by-side with the story that a warrant had been issued for the arrest of one of the main developers involved in the scheme set to benefit most from this infrastructure. The Irish property market has crashed spectacularly (Kitchinet al., forthcoming). Meanwhile, arts funding has been slashed and Cork has lost some important cultural venues. While schemes have subsequently been announced for the docklands, they come with so many caveats that it seems unlikely redevelopment will happen in the near future (O'Callaghan, 2011). The moment of the red balloons now seems like a culmination of a set of plans and relationships that ended in this snapshot; the wind failed to lift and the buildings coiled their briefly relaxed roots into the ground once more. The moment of change had passed.

As I currently see it, then, the image depicts two sets of ruins; the ruin of the industrial city that has ceased to be and the ruin of a particular version of the post-industrial city that never was. The former has a material basis, the latter a virtual. But, nevertheless, both ruins are implicated in how we perceive the image, and thus how we might experience the space that it depicts. As these buildings sit empty on the quay, they occupy a representational space between these two ruins, neither urban blight nor opportunity but quiet stasis, existing still in the lull between economic eras. 


\section{Lightness and weight}

Milan Kundera (1984) in Theunbearable lightness of being suggests the problematic of a dichotomy between the concepts of 'lightness' and 'weight'. Is lightness positive and weight negative? 'The only certainty is: the lightness/weight opposition is the most mysterious, most ambiguous of all', he suggests (Kundera, 1984: 5). Looking at this image I am reminded of this fragile opposition. In this picture which is lightness and which is weight? Depending on our acceptance of the piece's optical trick; are the buildings light, and thus the balloons have weight in order to lift them? To follow the metaphor through is heavy industry made light by art? Is the heaviness of Cork's industrial heritage made light (made removable) by the powerful vision of 'progress' encapsulated in the Docklands plans? And if so, is the apparatus of the neoliberal entrepreneurial city characterised by lightness or weight? Is the apparatus of entrepreneurial urbanism akin to the optical trick performed by this image, making that which is light appear to exert an oppressive weight of influence under which the lightness of opposing visions of the city cannot hope to combat?

This image of Cork encapsulates the way in which various forces and processes are combined with associations and assumptions to construct an imagining of the urban fabric that carries a weight to such an extent that it becomes 'real'. Urban projects like Cork Docklands demonstrate how powerfully images function within society. The bombardment of plans and visions of the area's transformation translate the space incrementally from one associated with one thing (industrial) to another (postindustrial). These visions 'order' the city, but do so 'cosmetically' by accentuating certain relationships (and thus fixing the city through a discursive imaginary) and not by organising the multiplicity. Serres (1985: 32-35) suggests that ordering and adorning are one and the same:

The Greeks in their exquisite wisdom combined order and adornment in the same word, the art of adorning and that of ordering. 'Cosmos' designates arrangement, harmony and law, the rightness of things: here is the world, earth and sky, but also decoration, embellishment and ornamentation... Cosmos and cosmetics, appearance and essence have the same origin. Adornment equals order and embellishment is equivalent to law, the world appears ordered, at whatever level we consider phenomena. Every veil is a magnificently historiated display (Serres, 1985: 32).

For Serres ' $[\mathrm{t}]$ he question of the city goes far beyond the urban question. It concerns simultaneously the emergence of the collective, foundations and relations, forms of multiplicity, representations of the world...' (Hénaff, 1997: 63). Inherent in any ordering of phenomena is the containment of the multiple. As Assad (2005: 216) argues '...Western thought has opted for rational, explanatory clarity and epistemological linearity and pushed aside the nonsolvable and nonclarifiable into the 
realm of the nonscientific... [whereas Serres opted] to present his scientific discourse in a metaphoric, often allegorical form...' Serres' critique in this regard is that the rational, scientific, and linear discourse itself occludes the multiple through a cosmetic ordering.

On this view, the urban visions that order the city do not present a 'false' depiction, but rather apply a selective cosmetics that uncovers the essential elements of (and essentialises) the city. They are veils that simultaneously make visible and conceal. But they do so only relationally, in combination with other veils that conceal and reveal different histories and potential futures. Urban visions are, thus, both weighty and light, powerful and fragile. Ordering and representation are always bound up in, and eroded by, multiplicity. The urban narrative is pleated and temporally out-of-joint, encompassing thousands of abandoned dreams like dead leaves scattered around the body of progress. The aborted plans of expansion, the discursive visions never to given material form, are not the inconsequential aberrations of a fundamentally linear march of time and space. They are the remainder of the creative destruction of capitalism in the city that is denied by the illusion of eternal progress. These substantial (anti) visions are powerful in their capacity to disrupt the linear and logical view of progress seated within the vision of entrepreneurial and neoliberal capitalist accumulation.

In my rereading of this image, the weighty relationships it had represented for me (relationships that would 'structure' the future of the city) became light components of histories never to have been (they would not even 'structure' the past). Yet this reading also succumbs to a linear understanding of time and the city and separates the material from the discursive. If the vision of the Docklands held such a powerful grip on the urban imaginary, then surely it does not vanish in the instant that the redevelopment of the site no longer becomes commercially viable. The Dockland project 'exists', has been made to exist over the last decade through a few plans and strategies, hundreds of newspaper articles and speeches, countless conversations, negotiations, and schemes, and a couple of prominent developments. This vision is altered, perhaps loses its potency (its weight) in becoming a history never to have been instead of a future to be, but it remains folded in the urban fabric, pleated again (and again) into the city's histories. In doing so, it disrupts the linear (progress) vision.

Within the entrepreneurial city vision an unbroken trajectory between the past, present and future is articulated that denies urban spatial and temporal multiplicity and exerts a weight of inevitability to the city's development. But other cities are located in the interstices of this vision, hidden histories and veiled futures that interrupt the linear flow of time and space. In this article I have argued that because images are inscribed with these relationships and meanings they can also be mobilised to disrupt the ordered and static view of what cities can be. Nancy (1991) 
suggests that every collectivity is produced and transformed by continually 'unworking' itself through singular interventions that interrupt totalising meanings. The city as a collectivity is similarly unworked by such small-scale interventions that, rather than signifying a violent wakening from Benjamin's 'collective dream', involve a perpetual process of 'crumpling' the urban fabric to illuminate these other cities. Such interventions are not a radical departure for urban studies. But as capitalism regenerates after this most recent crisis, a critical agenda that seeks to continuously (iteratively) destabilise the weight of 'logic' presupposed within the neoliberal view of space and society is both warranted and necessary to keep the possibility of alternative urbanities in play.

Acknowledgements. I would like to thank the Irish Research Council for the Humanities and Social Sciences for funding the research project for which this photograph was originally produced. I would like to thank Denis Linehan, Helen Maulion, Rob Kitchin, and two anonymous reviewers for reading earlier drafts of this paper and offering insightful and encouraging comments. I would also like to thank Kevin Ward for his support, and Madeleine Hatfield for sorting out some formatting issues. I wish to thank Tara Byrne, former Director of the National Sculpture Factory for providing me with information on the 'Balloon' installation. Finally, thanks to Sorcha O'Brien and Eli Caamano for producing such a stimulating piece of public art. Any faults or errors remain my own.

\section{References}

Assad, M. (2005) 'Being free to write for a woman': the question of gender in the work of Michel Serres In: Abbas, N. ed., Mapping Michel Serres. Ann Arbor, MI: University of Michigan Press. 210-25.

Barker, T. (2008) Origin enterprises to submit planning application for docklands development. Irish Examiner, 11 March.

Bartley, B. and Kitchin, R. eds. (2007) Understanding contemporary Ireland. London: Pluto Press.

Benjamin, W. (1999) The Arcades Project. Harvard: Harvard University Press.

Buck-Morss, S. (1989) The dialectics of seeing: Walter Benjamin and the Arcades Project. Cambridge, MA: MIT Press.

Chang, T.C. and Huang, S. (2005) Recreating place, replacing memory: creative destruction at the Singapore River. Asia Pacific Viewpoint, 46, 267-80. 
Cork City Council (2002) Cork Docklands development strategy. Cork: Cork City Council.

Crang, M. (2003) The hair in the gate: visuality and geographical knowledge. Antipode, 35, 238-43

Crang, M. and Travlou, P. (2001) The city and topologies of memory. Environment and Planning D: Society and Space, 19. 161-77.

De Certeau, M. (1984) The practice of everyday life. Berkley, CA: University of California.

Deleuze, G. (1994) Difference and repetition. London: Continuum.

Edensor T (2005) Industrial ruins: space, aesthetics and materiality Berg, Oxford

Fyfe, G. and Law, J. (1988) Picturing power: visual description and social relations. London: Routledge.

Gibson, L. and Stevenson, L. (2004) Urban space and the uses of culture. International Journal of Cultural Policy, 10, 1-4.

Gilloch, G. (1997) Myth and metropolis: Walter Benjamin and the city. Bristol: Polity Press.

Gospodini, A. (2006) Portraying, classifying and understanding the emerging landscapes in the post-industrial city. Cities, 23, 311-30.

Hannigan, J. (1998) Fantasy city: pleasure and profit in the postmodern metropolis. London: Routledge.

Hénaff, M. (1997) Of stones, angles, and humans: Michel Serres and the global city SubStance, 26, 59-80.

Kitchin, R., O'Callaghan, C., Boyle, M., Gleeson, J. and Keaveny, K. (forthcoming) Placing neoliberalism: the rise and fall of Ireland's Celtic Tiger. Environment and Planning A.

Kong, L. (2000) Cultural policy in Singapore: negotiating economic and socio-cultural agendas. Geoforum, 31, 409-24.

Kundera, M. (1984) The unbearable lightness of being. London: Faber and Faber.

Lefebvre, H. (1991) The production of space. Oxford: Blackwell. 
Lorimer, H. (2003) Telling small stories: spaces of knowledge and the practice of geography. Transactions of the Institute of British Geographers, 28, $197-217$.

Merrifield, A. (2002) Metromarxism: a Marxist tale of the city. New York: Routledge.

Miles, M. (1997) Art, space and the city. London: Routledge.

Nancy, J. (1991) Literary communism In: The inoperative community (theory and history of literature). Minneapolis, MN: University of MinnesotaPress. 71-81.

O'Callaghan, C. (2011) What's going on with Cork Docklands? Ireland after NAMA. Available at:

http://irelandafternama.wordpress.com/2010/08/30/what $\%$ E2\%80\%99 s-going-on-with-corkdocklands /. (accessed 15 December 2011).

O'Callaghan, C. and Linehan, D. (2007) Identity politics and conflict in dockland development in Cork, Ireland: European Capital of Culture 2005. Cities, 24, 311-23.

Rose, G. (2003) On the need to ask how, exactly, is geography 'visual'? Antipode, 35, 212-21.

Rose, G. (2007) Visual methodologies: an introduction to the interpretation of visual materials. London: Sage.

Serres, M. (1985) The five senses: a philosophy of mingles bodies. London: Verso.

Serres, M. (1991) Rome: book of foundations. Stanford: Stanford University Press.

Serres, M. with Latour, B. (1995) Conversations on science, culture and time. Ann Arbor, MI: University of Michigan Press.

Soja, E. (2000) Postmetropolis: critical studies for cities and regions. Oxford: Blackwell. 